\title{
An Enzyme-Based Biosensor for the Detection of Organophosphate Compounds Using Mutant Phosphotriesterase Immobilized onto Reduced Graphene Oxide
}

\author{
Muhammad Syafiq Mohd Razib $\mathbb{D D}^{1},{ }^{1}$ Wahhida Latip $(\mathbb{D}),{ }^{2}$ Jahwarhar Izuan Abdul Rashid $(\mathbb{D}),{ }^{3}$ \\ Victor Feizal Knight $\mathbb{D}^{1},{ }^{1}$ Wan Md Zin Wan Yunus $\mathbb{D}^{4},{ }^{4}$ Keat Khim Ong $\mathbb{D}^{1}{ }^{1}$ \\ Noor Azilah Mohd Kasim (D), ${ }^{1}$ and Siti Aminah Mohd Noor (iD ${ }^{3}$ \\ ${ }^{1}$ Research Centre for Chemical Defence, National Defence University of Malaysia, Sungai Besi Camp, \\ Kuala Lumpur 57000, Malaysia \\ ${ }^{2}$ Enzyme and Microbial Technology Research Center, Faculty of Biotechnology and Biomolecular Sciences, \\ Universiti Putra Malaysia, Serdang 43400, Malaysia \\ ${ }^{3}$ Center for Defence Foundation Studies, National Defence University of Malaysia, Kem Perdana Sungai Besi, \\ Kuala Lumpur 57000, Malaysia \\ ${ }^{4}$ Centre for Tropicalisation, National Defence University of Malaysia, Sungai Besi Camp, Kuala Lumpur 57000, Malaysia
}

Correspondence should be addressed to Siti Aminah Mohd Noor; s.aminah@upnm.edu.my

Received 31 May 2021; Revised 17 June 2021; Accepted 23 June 2021; Published 5 July 2021

Academic Editor: Shahid Hussain

Copyright (c) 2021 Muhammad Syafiq Mohd Razib et al. This is an open access article distributed under the Creative Commons Attribution License, which permits unrestricted use, distribution, and reproduction in any medium, provided the original work is properly cited.

\begin{abstract}
Enzymatic detection of organophosphate (OP) compounds can be tailored using highly sensitive and selective enzymes in the development of biosensors. Previously, mutant (YT) phosphotriesterase (PTE) was reported to efficiently hydrolyze Sp and Rp enantiomers of phosphotriester. This study reports the use of phosphotriesterase mutant YT (YT-PTE) immobilized onto reduced graphene oxide ( $\mathrm{rGO}$ ) and fabricated onto a screen-printed carbon electrode (SPCE) for electrochemical detection of OP compounds. Immobilization of YT-PTE onto rGO was secured using N-hydroxysuccinimide (NHS) and N-(3-dimethylaminopropyl)-N'-ethylcarbodiimide (EDC) cross-linker, and the resulting immobilized enzyme was able to retain up to $90 \%$ of its activity. Electrochemical analysis of the SPCE/rGO/YT-PTE showed detection of paraoxon in a linear range of $1 \mathrm{mM}-0.005 \mu \mathrm{M}$ with its limit of detection as low as $0.11 \mu \mathrm{M}$. SPCE/rGO/YT-PTE exhibited high selectivity towards paraoxon and parathion and have good reproducibility. Furthermore, detection of paraoxon was also possible in a real water sample with only minor interferences.
\end{abstract}

\section{Introduction}

The use of agricultural and domestic pesticides is a common practice among farmers and plant breeders for the purpose of protecting their crops from pests so that high-quality produce with high marketability can be cultivated. Increases in the use of pesticides, however, have raised public concerns over the possibility of leachate contamination of such pesticides in water sources, food sources, and the environment as a whole [1]. Organophosphate (OP) compounds are examples of a group of toxic compounds that are presently used as pesticides. Apart from being a major constituent in many brands of pesticide, OP compounds such as paraoxon, parathion, and malathion are also used to make plasticizers and other insecticides and even misused as chemical warfare agents [2-5]. OP compounds are known to be inhibitors towards the enzyme acetylcholine esterase (AChE), an enzyme that is crucial for the functional operation of the nervous system. Inhibition of the enzyme AChE has neurotoxic effects on humans and animals as it disrupts the transfer of neurotransmitters, which will result in paralysis and ultimately cause death $[6,7]$. Cases 
involving OP compound pollution have been reported over the past few years and these numbers are increasing at an alarming rate $[1,8,9]$.

The development of portable sensors utilizing functional materials, polymers, and biomolecules is seen to ease the process of analysis through the use of more simplified methods [10]. One manner of performing such detection is through the use of enzymes as bioreceptors for the desired compound. The use of enzymes in biosensors is deemed to be favorable due to its specificity and selectivity towards specific substrates. Organophosphate hydrolase $(\mathrm{OPH})$ is an enzyme capable of hydrolyzing the $\mathrm{P}-\mathrm{O}$ bonds of $\mathrm{OP}$ compounds, thus releasing the radicals that contribute to the toxicity of the compound and thereby rendering it neutralized $[11,12]$.

Phosphotriesterase (PTE), a type of $\mathrm{OPH}$, has been shown to be able to hydrolyze OP compounds such as paraoxon and parathion exceptionally well $[13,14]$. Tsai et al. have highlighted a specific PTE variant known as mutant H257Y/L303 T (YT-PTE), which exhibits enhanced hydrolysis affinity towards a series of toxic enantiomers of the OP compound [15]. In addition to high affinity towards various OP compound enantiomers, they also exhibit enhanced kinetic value resulting in a faster hydrolysis rate of OP compound than other mutant variants and wild-type PTE [15]. This enzyme is a suitable candidate for the development of a biosensor utilizing an on-site detection method where the $\mathrm{OPH}$ will act as a bioreceptor that is fabricated onto a screen-printed electrode to allow for the electrochemical detection of specific OP compounds [16]. In addition to the detection ability against OP compounds, using PTE as a biosensor is a technique that can be done in a relatively short amount of time and both the electrode and enzyme are relatively inexpensive [17].

In various works in the literature, it has been described that the detection of OP compounds utilizing enzymes has been conducted via either an electrochemical approach $[18,19]$ or an optical approach $[20,21]$. In the electrochemical approach, $\mathrm{OPH}$ is usually immobilized onto nanomaterial supports such as carbon nanotubes (CNTs), carbon black, mesoporous carbon, and graphene. The use of these carbon-based nanomaterial supports is appealing since these materials are relatively inexpensive, have good conductive properties, and are easy to handle [22]. The immobilization of $\mathrm{OPH}$ onto conductive nanomaterials facilitates electron transfer within the sensor system since biomolecules such as enzymes on their own are generally nonconductive in nature [23]. Nowadays, the use of graphene oxide (GO) as nanomaterial support has gained some interest among researchers due to its structural and electrochemical properties. Although GO can be tailored to have many functional groups on the surface that can efficiently bind any biomolecule [24], the presence of oxide layers could reduce the electrochemical sensing performance in terms of redox activities [25]. As a result, in order to eliminate oxide layers, the GO has to go through the reduction process, forming reduced graphene oxide (rGO). rGO has gained interest in electrochemical sensing due to its unique properties, including high surface area [26], low manufacturing cost [27], good biocompatibility [28], outstanding mechanical flexibility [29], and high thermal and electrical conductivity [30-32]. The utilization of rGO as a biorecognition also has been widely used for electrochemical sensing, such as cortisol hormone [33,34], cancer biomarker [35], dopamine [36], glucose [37], human T-lymphotropic virus-1 (HTLV-1) [38], and DNA [39]. However, earlier studies have not yet reported on the combination of YT-PTE with $\mathrm{rGO}$ as a new biorecognition for OP detection, which is seen as an interesting work to explore. Hence, this work reports the immobilization of phosphotriesterase YT mutant (YT-PTE) onto reduced graphene oxide (rGO) as a promising bioreceptor, with high affinity and high specificity, for use in the electrochemical detection of OP compounds.

\section{Materials and Methods}

2.1. Chemicals, Reagents, and Apparatus. The gene sequence of the crystal structure of YT-PTE was obtained from the protein data bank (PDB ID 2OB3). This gene was synthesized by Apical Sdn. Bhd., Selangor, Malaysia, and was subcloned into pET51b and expressed in E. coli BL21 (DE3). Yeast extract and tryptone were purchased from Oxoid (Hampshire, UK). Ammonium sulfate $\left[\left(\mathrm{NH}_{4}\right)_{2} \mathrm{SO}_{4}\right]$, potassium dihydrogen phosphate $\left(\mathrm{KH}_{2} \mathrm{HPO}_{4}\right)$, sodium hydrogen phosphate $\left(\mathrm{NaHPO}_{4}\right)$, magnesium sulfate heptahydrate $\left(\mathrm{MgSO}_{4} \cdot 7 \mathrm{H}_{2} \mathrm{O}\right)$, sodium sulfate $\left(\mathrm{Na}_{2} \mathrm{SO}_{4}\right)$, $\mathrm{D}-(+)$-glucose, N-hydroxysuccinimide (NHS), and $\mathrm{N}-(3-$ dimethylaminopropyl)-N'-ethylcarbodiimide (EDC) were purchased from Merck (Kenilworth, NJ). Amine-functionalized reduced graphene oxide (rGO), glycerol, $\alpha$-lactose, paraoxon-ethyl, and phosphate buffer saline (PBS) solution were purchased from Sigma-Aldrich (St. Louis, MO). Ampicillin was purchased from Gold Biotechnology (St. Louis, MO). Solvents used in this research were of analytical grade, including ethanol, which was purchased from R\&M Chemicals (Essex, UK). Screen-printed carbon electrodes (SPCE) were purchased from DropSens (Oviedo, Spain). The electrochemical analysis was conducted using an Autolab PGSTAT 204 potentiostat. All solutions used in this research were prepared with double-distilled water.

\subsection{Expression and Purification of PTE. E. coli BL21 har-} boring pET51b/YT-PTE was grown in autoinduction media following the method of Studier [40] with glucose as the primary source of carbon and $\alpha$-lactose as the inducer. The starting culture was inoculated in $400 \mathrm{~mL}$ of autoinduction media supplemented with $50 \mu \mathrm{g} / \mathrm{mL}$ ampicillin and grown in an incubator shaker at $37^{\circ} \mathrm{C}, 150 \mathrm{rpm}$ for $3 \mathrm{~h}$. The temperature was then reduced to $25^{\circ} \mathrm{C}$ and the culture was further incubated for $24 \mathrm{~h}$. Next, the culture was centrifuged at $4^{\circ} \mathrm{C}$, $10000 \mathrm{rpm}$ for $10 \mathrm{mins}$, resuspended in $0.1 \mathrm{M}$ Tris- $\mathrm{Cl}$ buffer ( $\mathrm{pH}$ 9.3), and sonicated thrice with intermittent timing of 30 secs to obtain the soluble crude PTE. Purification of the PTE was conducted using anion exchange chromatography XK16/20 column (GE Healthcare, USA) packed with Q-sepharose resin. The column was equilibrated with $0.1 \mathrm{M}$ 
Tris-Cl buffer ( $\mathrm{pH}$ 9.3) prior to loading of the crude enzyme and was washed five times to remove any unbound proteins. The bound protein was then eluted with $0.1 \mathrm{M}$ Tris-Cl buffer ( $\mathrm{pH}$ 9.3) supplemented with $0.5 \mathrm{M} \mathrm{NaCl}$.

2.3. Assay of Phosphotriesterase Activity. The enzyme activity of PTE was measured using paraoxon as the substrate following the method of Laothanachareon et al. [41] with slight modification. $100 \mu \mathrm{L}$ of $1 \mathrm{mM}$ paraoxon was mixed with $890 \mu \mathrm{L}$ of PBS solution prior to the addition of $10 \mu \mathrm{L}$ of the enzyme in a microcentrifuge tube. The mixture was briefly mixed by vortexing and was incubated at $30^{\circ} \mathrm{C}$ for 10 minutes. The reaction was terminated by adding $200 \mu \mathrm{L}$ of absolute ethanol. The supernatant of the mixture was collected for absorbance reading at $A_{400}$. A unit of phosphotriesterase activity was defined as the production of one mol of p-nitrophenol (pNP) per minute under standard conditions.

\subsection{Construction of the Sensing Electrode SPCE/rGO/YT-PTE.} A $1 \mathrm{mg} / \mathrm{mL}$ of reduced graphene oxide ( $\mathrm{rGO}$ ) suspension was dispersed to homogeneity in PBS buffer solution by ultrasonication for 10 mins. An equal amount of $5 \mathrm{mM}$ EDC-NHS solution as the cross-linker was added and the mixture was incubated at $4^{\circ} \mathrm{C}$ with mild shaking for $1 \mathrm{~h}$. The mixture was then centrifuged at $10000 \mathrm{rpm}$ for $5 \mathrm{mins}$ and the supernatant was discarded. The pallet of rGO obtained was washed with PBS buffer for a few times to remove any residual EDC-NHS. Different concentrations of PTE $(2,4,6$, 8 , and $10 \mathrm{mg} / \mathrm{mL}$ ) were added to the mixture and further incubated at $4^{\circ} \mathrm{C}$ with mild shaking for $16 \mathrm{~h}$. These concentrations of YT-PTE represented different rGO to enzyme ratios which were $1: 2,1: 4,1: 6,1: 8$, and $1: 10$, respectively. After the incubation period, the mixture was once again centrifuged at $10000 \mathrm{rpm}$ for $10 \mathrm{~min}$ and the pellet of immobilized YT-PTE onto rGO was collected for fabrication onto a blank SPCE. $5 \mu \mathrm{L}$ of the immobilized YT-PTE was drop-casted onto the working electrode of the SPCE and was allowed to air dry at $4^{\circ} \mathrm{C}$ overnight. The construct of the $\mathrm{SPCE} / \mathrm{rGO} / \mathrm{YT}-\mathrm{PTE}$ is illustrated in Scheme 1.

2.5. Measurement Procedure. The incubation time of the substrate is crucial for electrochemical analysis as sufficient incubation time for the reaction to occur between the enzyme and the substrate is needed to ensure a significant peak current to be detected for analysis. The optimum incubation time for the biosensor was determined by incubating $1 \mathrm{mM}$ paraoxon on the biosensor platform for 5, 10, 15, and 20 minutes. The time when the peak current reached saturation point was chosen to be the optimum incubation time for the biosensor. It was found that 10 minutes was the optimal incubation time. Then, $10 \mu \mathrm{L}$ of $1 \mathrm{mM}$ paraoxon was dropped onto the surface of the modified working electrode as the substrate and was allowed to react with the immobilized PTE for $10 \mathrm{~min}$. After this reaction time, $90 \mu \mathrm{L}$ of $5 \mathrm{mM} \mathrm{Fe}_{3}(\mathrm{CN})_{6}$ solution supplemented with $0.1 \mathrm{M} \mathrm{KCl}$ as the electrolyte was dropped onto the surface of the modified electrode, and the electrochemical analysis was recorded using cyclic voltammetry (CV) and differential pulse voltammetry (DPV). The potential range of $\mathrm{CV}$ and $\mathrm{DPV}$ analysis was set in the range of -1.0 to $1.0 \mathrm{~V}$ and -0.2 to $0.4 \mathrm{~V}$ with a scan rate of $50 \mathrm{mV} / \mathrm{s}$ and $10 \mathrm{mV} / \mathrm{s}$, respectively.

\section{Results and Discussion}

3.1. Characterization of the Modified Electrode. In recent time, amine-functionalized rGO has been shown to exhibit better water dispersal [42], reinforce stability, and improve affinity towards redox reaction [43]. Apart from that, it provides numerous amine functional groups for the formation of amide bond linkages during the interaction with EDC-NHS cross-linkers [23]. Enzyme cross-linking typically occurs within the amine group of the amino acid residues; nevertheless, the formation of linkages can also found within the carboxylic group of the amino acid residues [44, 45]. The addition of EDC-NHS cross-linkers activates the amino group of rGO prior to covalent attachment to the carboxylic group of the enzyme, as illustrated in Scheme 2. This interaction forms a strong amide bond, which held the enzyme onto the support securely and provided structural support for the enzyme.

The formation of immobilized YT-PTE onto the rGO was confirmed by morphological analysis using a Field Emission Scanning Electron Microscopy (FESEM). FESEM analysis was conducted on two samples, SPCE/rGO and $\mathrm{SPCE} / \mathrm{rGO} / \mathrm{YT}$-PTE, and the difference in their morphologies was compared and recorded. The morphology of SPCE/rGO appeared to be flaky and have a crumpled appearance as shown in Figure 1(a). Immobilization of YTPTE onto rGO changed the morphology of SPCE/rGO/YTPTE into a more compact and smoother appearance as shown in Figure 1(b). This morphology is attributed to the formation of an immobilized YT-PTE layer on top of rGO, which inadvertently indicated the success of immobilization of the enzyme onto rGO surfaces [46].

Electrochemical analysis of conductivity and resistivity of SPCE/rGO/YT-PTE and SPCE/rGO/YT-PTE was conducted using cyclic voltammetry $(\mathrm{CV})$ and Electrochemical Impedance Spectroscopy (EIS). rGO was fabricated onto SPCE to enhance the conductivity of the biosensor and to act as a carrier for immobilizing the YT-PTE [47]. The 2D structure of rGO enables the fast flow of electrons between the $\mathrm{Fe}_{3}(\mathrm{CN})_{6}$ analyte and the working electrode, owing to its good conductivity characteristics. As was expected, the enzyme YT-PTE, which is a nonconductive biomolecule, and its immobilization onto the working electrode increased the resistance against electron flow. The resistivity of YTPTE was analyzed with CV and EIS and this is illustrated in Figures 2(a) and 2(b), respectively.

$\mathrm{CV}$ analysis of the biosensor, as compared to a bare SPCE, displayed an increase of the CV anodic peak by $58.2 \%$ when $\mathrm{rGO}$ was fabricated onto the SPCE in contrast with YT-PTE immobilized onto rGO, which recorded an increment of only $8.0 \%$. The EIS analysis measured the frequency of electron transfer, which is then illustrated as a semicircle-shaped Nyquist plot. The Nyquist plot from the 


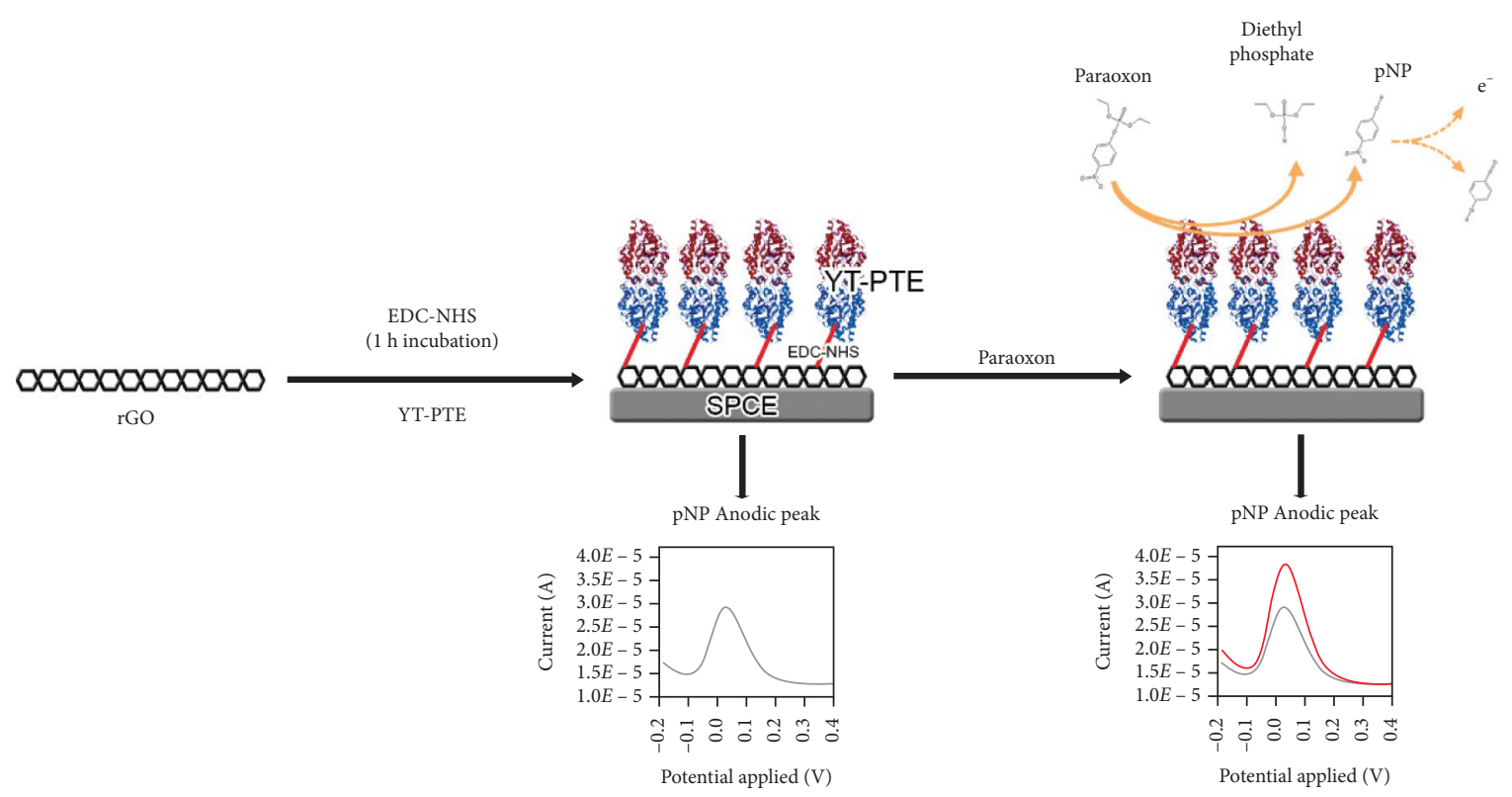

SCHEme 1: Schematic illustration of the construction of SPCE/rGO/YT-PTE for detection of OP compounds.

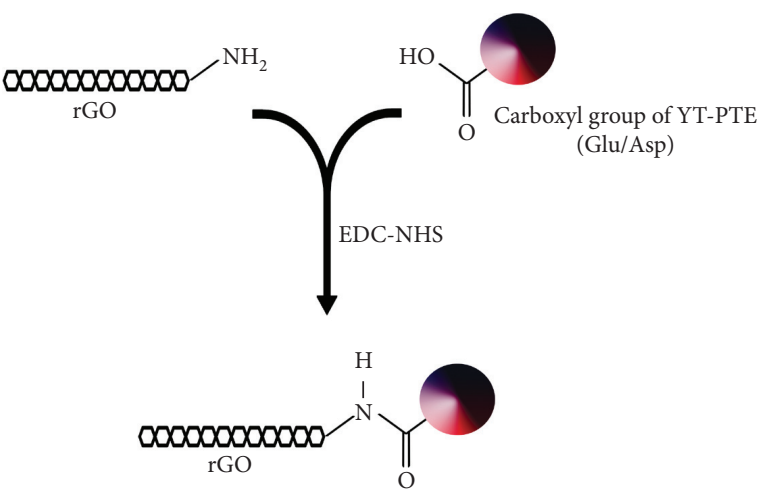

Scheme 2: Immobilization of YT-PTE onto rGO via EDC-NHS cross-linking $[35,36]$.

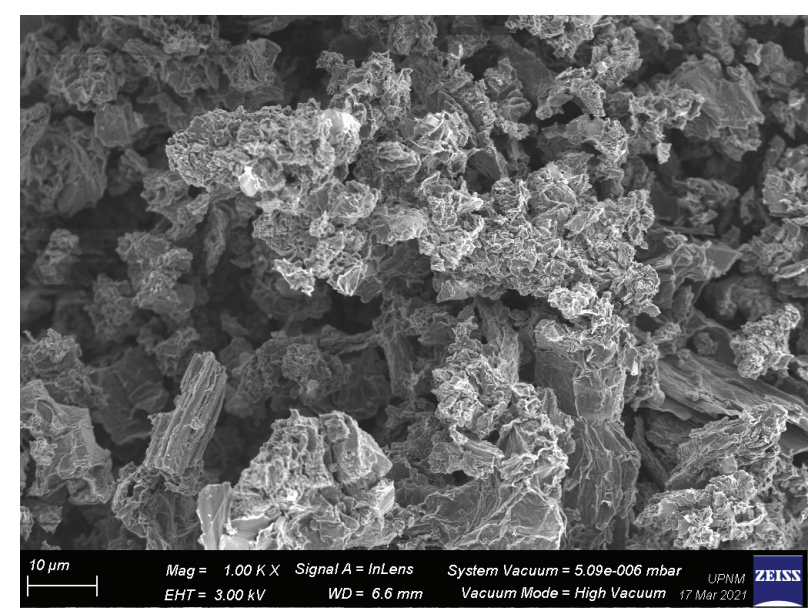

(a)

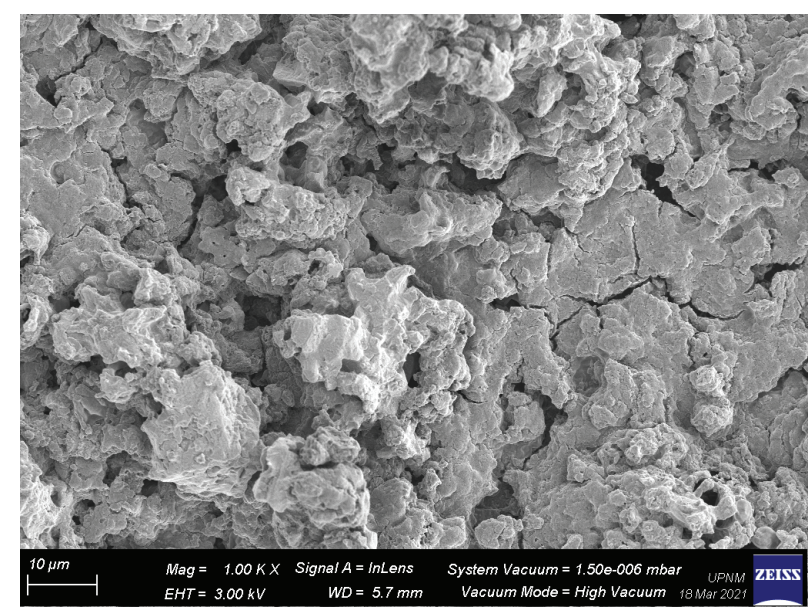

(b)

Figure 1: FESEM images of (a) SPCE/rGO/YT-PTE and (b) SPCE/rGO/YT-PTE under 1000 $x$ magnification. 


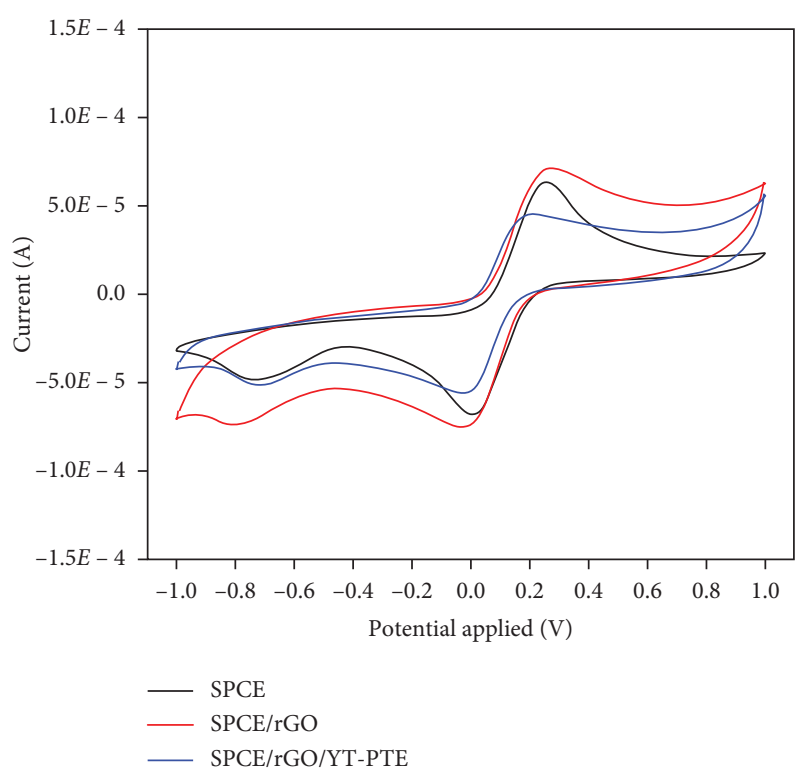

(a)

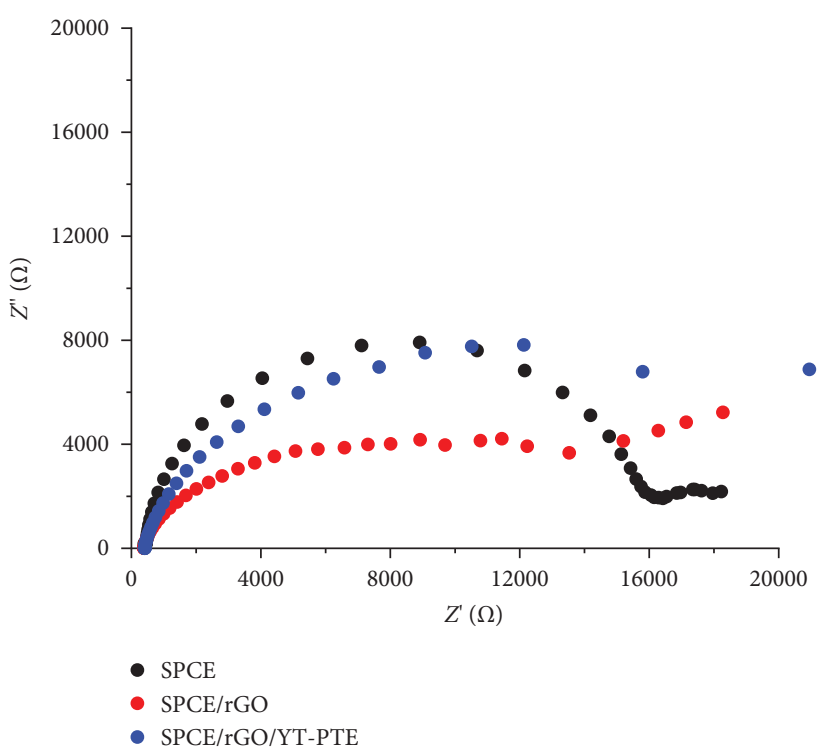

(b)

Figure 2: (a) Cyclic voltammograms of SPCE, SPCE/rGO, and SPCE/rGO/YT-PTE in $5 \mathrm{mM} \mathrm{Fe}{ }_{3}(\mathrm{CN})_{6}$ supplemented with $0.1 \mathrm{M} \mathrm{KCl}$ solution and (b) Nyquist plot of EIS of SPCE, SPCE/rGO, and SPCE/rGO/YT-PTE in $5 \mathrm{mM} \mathrm{Fe}{ }_{3}(\mathrm{CN})_{6}$ supplemented with $0.1 \mathrm{M} \mathrm{KCl}$ solution.

EIS analysis revealed that the Rct value, which determined the resistivity by measuring the diameter of the semicircle of the Nyquist plot, of SPCE/rGO/YT-PTE was recorded at $23.2 \mathrm{k} \Omega$ as compared to the Rct value of SPCE/rGO, which was recorded at $17.4 \mathrm{k} \Omega$. The incorporation of YT-PTE as a bioreceptor onto the surface of the electrode formed a nonconductive layer, which disrupted the electron flow, explaining the changes observed in the CV and EIS analysis of SPCE/rGO and SPCE/rGO/YT-PTE, respectively.

3.2. Mechanism of Electrochemical Detection. In this work, we utilized the enzymatic reaction between YT-PTE and paraoxon to the basis for the development of a biosensor that is able to determine the level of paraoxon present. In the presence of paraoxon, immobilized YT-PTE hydrolyzes the $\mathrm{P}-\mathrm{O}$ bond in paraoxon to the corresponding diethyl phosphate and p-nitrophenol (pNP) as shown in Scheme 3. Since the amount of pNP generated is proportionate to the amount of OP compound present in the sample $[6,12,48]$, the level of paraoxon can thus be quantified by the electrochemical oxidation signal of pNP that couples with $\mathrm{Fe}_{3}(\mathrm{CN})_{6}$ redox molecules as the form of signal amplification. In general, as the concentration of paraoxon increases, more pNP molecules can be generated and oxidized, thus resulting in an increase in the electrochemical current signal present.

3.3. Optimization of the Biosensor. The performance of the biosensor depends on the enzyme activity of YT-PTE. The amount of support to enzyme ratio (rGO:YT-PTE) needs to be optimized to ensure maximum enzyme activity recovery. The amount of rGO used in this study was fixed at $1 \mathrm{mg} / \mathrm{mL}$, following the method described in previous works of literature $[23,53]$. Different concentrations of YT-PTE (2, $4,6,8$, and $10 \mathrm{mg} / \mathrm{mL}$ ) were mixed and allowed to be immobilized onto rGO. Figure 3(a) shows the recovered activity of the YT-PTE after being immobilized onto various concentrations of rGO. It can be seen that the recovered activity of immobilized PTE increased when higher concentrations of PTE were used, up to $1: 8$ support to enzyme ratio, and it shows the optimum recovered activity of up to $90 \%$, which eventually decreased at the 1:10 ratio. Maximum loading of enzyme depended on the structure and conformation of the nanomaterial support. The use of EDCNHS as a cross-linker formed secure linkages, which held YT-PTE securely on the rGO despite the fact that it is difficult to adhere the enzyme onto a $2 \mathrm{D}$ planar configured nanomaterial. Inadvertently, the simple planar configuration of rGO was found to not have a detrimental effect upon YTPTE since up to $90 \%$ of enzyme activity was recovered after the enzyme underwent the immobilization processes.

The use of a nonbiocompatible redox solution, $\mathrm{Fe}_{3}(\mathrm{CN})_{6}$, had a detrimental effect on the immobilized enzyme. This solution disrupts the structural conformation of the enzyme, especially its active sites, thus rendering it denatured $[54,55]$. This caused major concern since the detection mechanism of this sensor relies on the hydrolysis of OP compounds by the enzyme. For that reason, the substrate was allowed to react with the enzyme first prior to the addition of the redox solution for electrochemical analysis of the hydrolysis product. The incubation time for hydrolysis of the OP compound was investigated at $5 \mathrm{~min}$ intervals. As shown in Figure 3(b), the peak current detected for pNP increased with increasing the incubation time from 0 mins to 10 mins. The peak current was recorded at a plateau level 


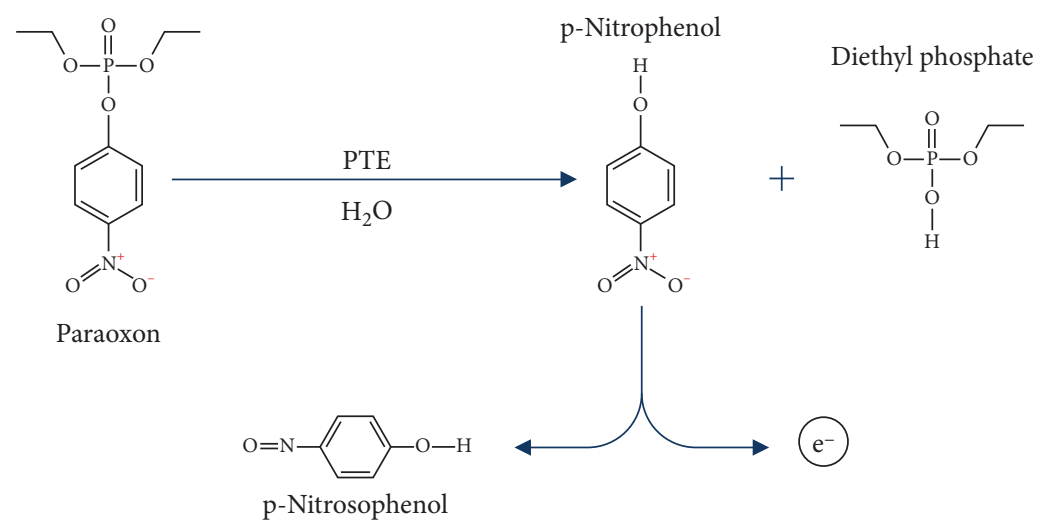

Scheme 3: p-Nitrophenol electrochemical oxidation pathway [49-52].

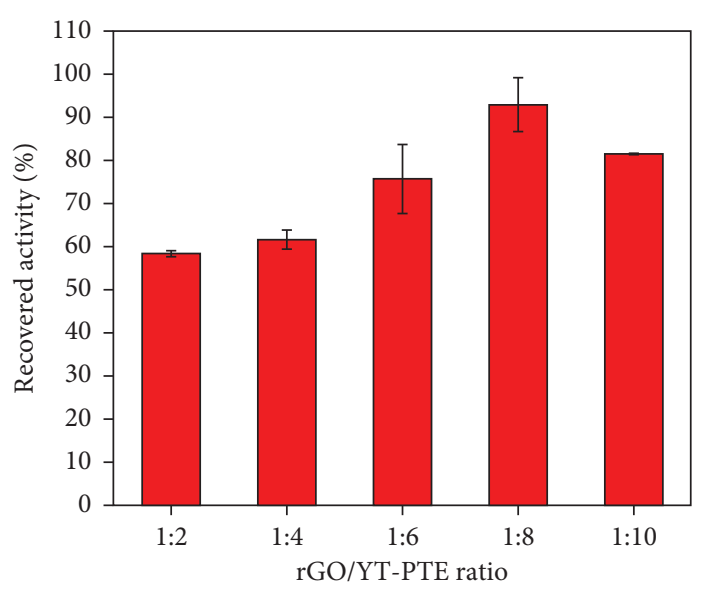

(a)

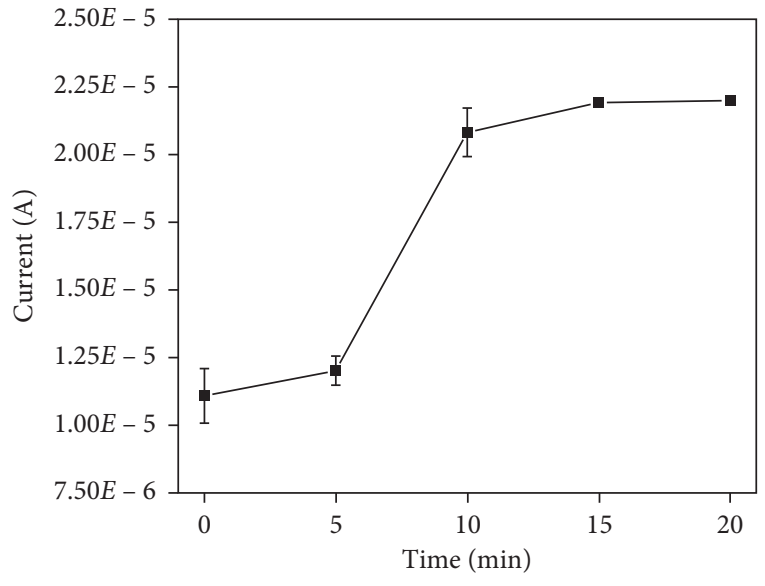

(b)

FIgUre 3: (a) Optimization of support to enzyme ratio (rGO : PTE); (b) effect of substrate incubation time on the electrochemical analysis.

when the time reached 10 mins, which signaled the completion of the hydrolysis reaction. Therefore, 10 mins was chosen as the optimal substrate incubation time prior to the addition of the redox solution for electrochemical analysis.

3.4. Electrocatalytic Analysis of SPCE/rGO/PTE. The performance of SPCE/rGO/YT-PTE was investigated in a series of paraoxon dilutions, which were measured with differential pulse voltammetry (DPV). The effect of different concentrations of paraoxon was tested using concentrations ranging between $1 \mathrm{mM}$ and $0.5 \mu \mathrm{M}$. The DPV peak resulted in an anodic peak about $+0.1 \mathrm{~V}$ (Figure $4(\mathrm{a})$ ), which corresponds to pNP oxidation in the $\mathrm{Fe}_{3}(\mathrm{CN})_{6}$ redox solution. In general, as the concentration of paraoxon rises, the oxidation peak rises, which occurred at $+0.1 \mathrm{~V}$, correlating with the fact that the amount of pNP generated is proportional to the amount of paraoxon found in the sample $[6,12,48]$. While the emergence of an anodic oxidation peak of pNP is often very small, the incorporation of $\mathrm{rGO}$ as a support for the immobilization of YT-PTE greatly enhanced this oxidation signal [56]. Figure 4(b) represents the relationship between the logarithm concentration of paraoxon and the peak current, which was illustrated by the linear expression $y=-1.99 E-06 x+6.9 E-06$ with an $R^{2}$ value of 0.9151 . The calibration curve demonstrated a linear relationship between the $-\log _{10}$ concentration of paraoxon and the DPV peak current signal. The limit of detection (LOD) of the biosensor was calculated at $0.11 \mu \mathrm{M}$. The LOD calculated in this work was equivalent to the LOD of other OPH-based OP biosensors reported in the literature (see Table 1). The prominent advantages of YT-PTE were that it had high sensitivity towards paraoxon in particular and further modifications such as the incorporation of nanoparticles or metal oxides could be done to increase the potential sensitivity of the biosensor [58].

3.5. Evaluation of the Biosensor. The reproducibility of the SPCE/rGO/YT-PTE biosensor was determined by fabricating the immobilized YT-PTE onto different SPCEs prior to electrochemical analysis using $1 \mathrm{mM}$ paraoxon as the substrate. The analysis was conducted weekly over a period of five weeks. As shown in Figure 5(a), the peak current of the various fabricated SPCEs is measured around $4.8 \mu \mathrm{A}$ with a standard deviation of $0.95 \mathrm{nA}$. This analysis indicates that the SPCE/rGO/YT-PTE had good reproducibility for use as a biosensor in the detection of OP compounds. The 


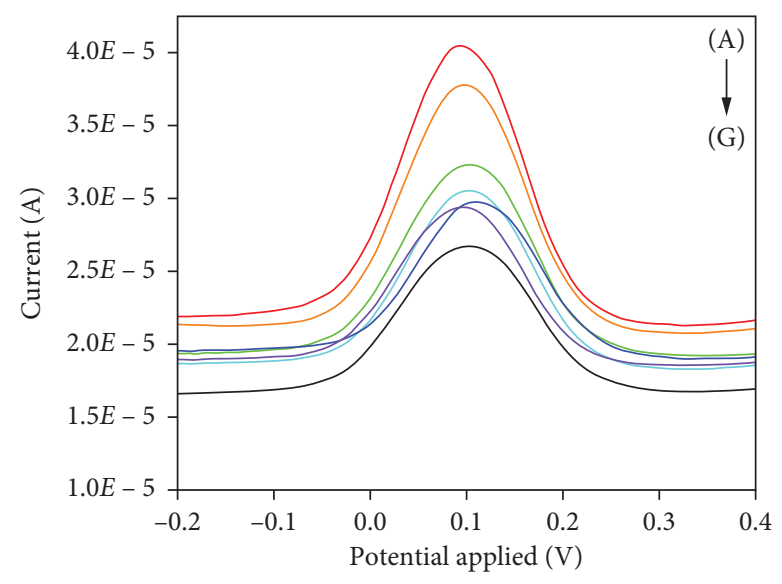

(a)

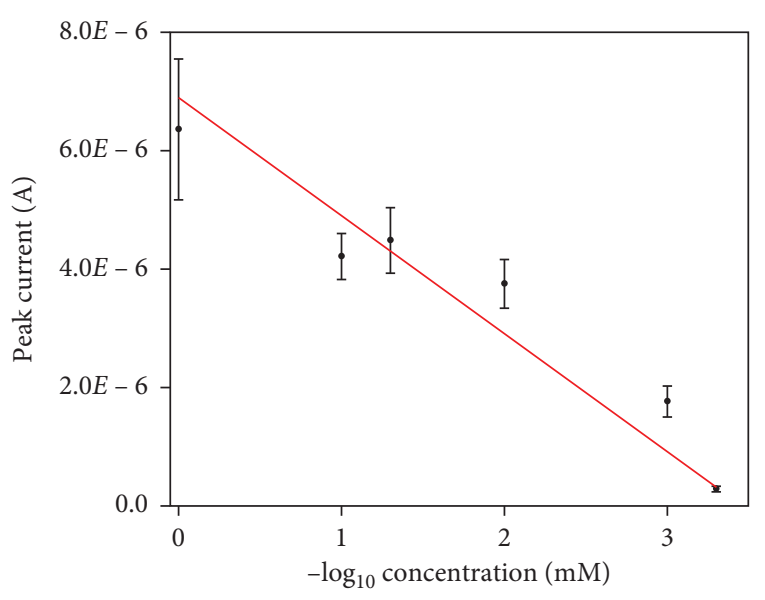

(b)

Figure 4: (a) DPV peak curve of different concentrations of paraoxon: (A) $1 \mathrm{mM}$, (B) $0.1 \mathrm{mM}$, (C) $0.05 \mathrm{mM}$, (D) $0.01 \mathrm{mM}$, (E) $1 \mu \mathrm{M}$, (F) $0.5 \mu \mathrm{M}$, and (G) $0 \mathrm{mM}$; (b) linear calibration curve of paraoxon concentration.

TABle 1: Comparison of SPCE/rGO/YT-PTE with other OP biosensors as reported in the literature.

\begin{tabular}{lcccc}
\hline Enzyme & Immobilization approaches & Substrate & LOD & References \\
\hline OPH & Covalent bonding onto AuNP-rGO & Diazinon & $0.302 \mu \mathrm{M}$ & {$[57]$} \\
OPH & Adsorption onto RGO/IL-modified Au electrodes & Paraoxon & $2 \mu \mathrm{M}$ & {$[46]$} \\
OPH & Adsorption onto MWCNTs & Paraoxon & $25 \mu \mathrm{M}$ & {$[19]$} \\
OPH & Adsorption onto BSA/TiO $/$ OPH/CNT & Methyl-parathion & $12 \mathrm{nM}$ & {$[18]$} \\
OPH & Adsorption onto MC/CB & Paraoxon & $0.12 \mu \mathrm{M}$ & $0.11 \mu \mathrm{M}$ \\
PTE & Covalent bonding onto rGO & Paraoxon & This work \\
\hline
\end{tabular}

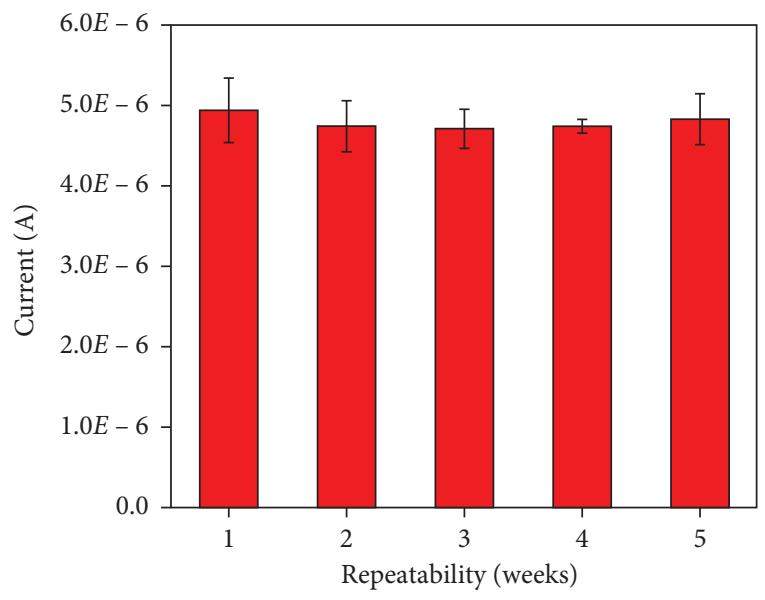

(a)

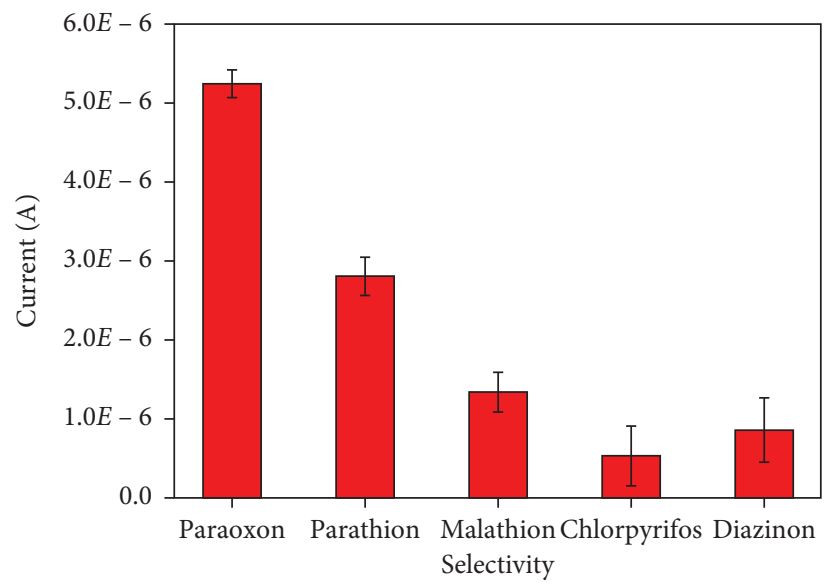

(b)

Figure 5: (a) Repeatability of SPCE/rGO/YT-PTE tested by different week and (b) selectivity studies of different substrates.

selectivity of the fabricated electrode was tested using $1 \mathrm{mM}$ of different substrates: paraoxon, parathion, malathion, chlorpyrifos, and diazinon. Based on Figure 5(b), paraoxon displayed the highest current signal followed by parathion. This is due to the nature of YT-PTE, which had a higher hydrolysis affinity towards phosphotriesterases such as paraoxon and parathion [59, 60]. The higher affinity towards these two compounds could be attributed to the structural homogeneity that each other shared, as shown in Figure 6 . The only difference between these two compounds was the presence of a P-S bond in parathion as compared to $\mathrm{P}-\mathrm{O}$ bonds in paraoxon [16]. Consequently, weaker current signals were detected with malathion, chlorpyrifos, and diazinon due to the different phosphorus bond types found with these OP compounds.

3.6. Application of the Biosensor in a Real Water Sample. Since OP compounds are commonly used for various agricultural purposes, as mentioned earlier, these 


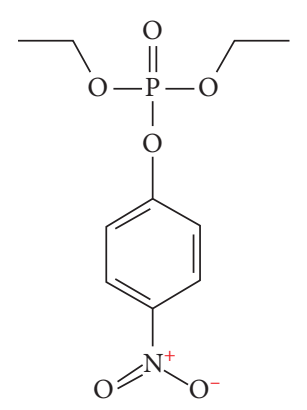

(a)

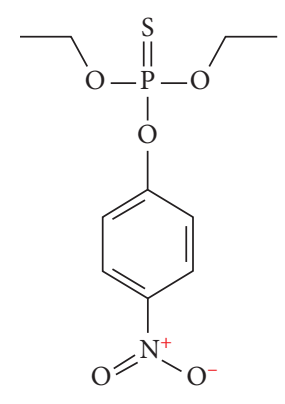

(b)

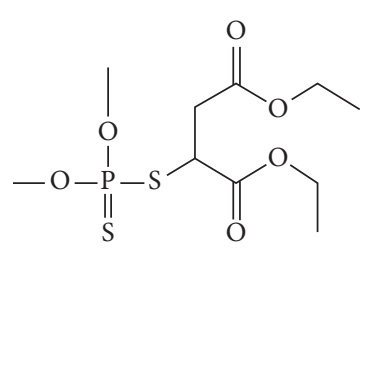

(c)

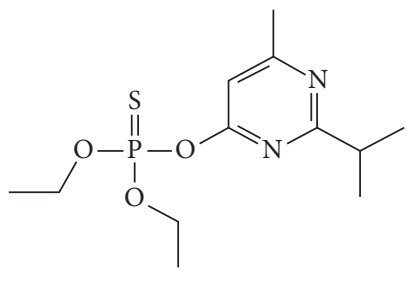

(d)

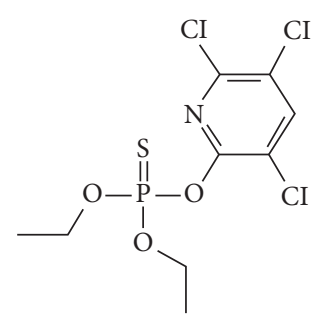

(e)

Figure 6: Molecular structure of different OP compounds. (a) Paraoxon, (b) parathion, (c) malathion, (d) diazinon, and (e) chlorpyrifos.

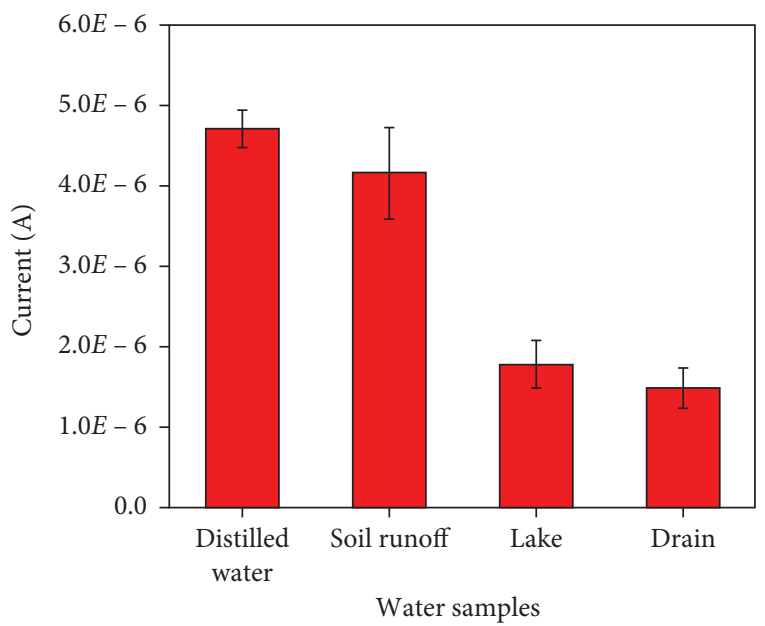

FIGURE 7: Detection of $1 \mathrm{mM}$ paraoxon in different spiked water samples.

compounds are often found leached into nearby water sources $[61,62]$. This poses a serious threat as the contamination can directly affect public health, both human and animal. The detection of OP compounds in real water samples using the SPCE/rGO/YT-PTE biosensor was tested by spiking different water samples: lake water, drain water, and soil run-off water, with $1 \mathrm{mM}$ of paraoxon. As shown in Figure 7, the current signal of distilled water (a sample with minimal or no interferences) spiked with paraoxon exhibited is $4.72 \pm 0.985 \mu \mathrm{A}$, while for the soil run-off water sample, the current signal was $4.17 \pm 0.465 \mu \mathrm{A}$. It can be clearly seen that the values of the current signal reduce only around $11 \%$. Moreover, in lake water and drain water, the current signal reduces to $1.79 \pm 0.502 \mu \mathrm{A}$ and $1.50 \pm 0.434 \mu \mathrm{A}$, respectively. It is expected due to high interference from environmental changes such as salinity, temperature, and $\mathrm{pH}$ that will affect the enzyme activity. The detection of current signals in these samples varied as the different water samples harbored different interference levels towards the biosensor. Nevertheless, the changes in the current signal with and without the presence of paraoxon can still be obtained. It was thus ascertained that the SPCE/rGO/YT-PTE biosensor system could be utilized for the detection of OP compounds in various water samples.

\section{Conclusion}

In general, YT-PTE immobilized onto rGO was able to retain up to $90 \%$ of its enzyme activity as compared to the free enzyme. Subsequently, the incorporation of rGO as the support for immobilizing YT-PTE aided in the electron transfer flow within the biosensor. The constructed biosensor was also shown to be able to detect the oxidation signal of pNP, which is a product of enzymatic hydrolysis of paraoxon. The electrochemical sensor utilizing rGO and YTPTE in this work recorded a linear range of $1 \mathrm{mM}-0.05 \mu \mathrm{M}$ with a detection limit measured at $0.11 \mu \mathrm{M}$. In addition to that, the biosensor showed selectivity towards different OP compounds, especially paraoxon and parathion. Immobilization of YT-PTE onto rGO resulted in a good bioreceptor, which can easily be fabricated onto SPCE for fast and portable field detection of OP compounds in real environmental water samples.

\section{Data Availability}

The data used to support the findings of this study are included within the article.

\section{Conflicts of Interest}

The authors declare that they have no conflicts of interest.

\section{Acknowledgments}

The authors are grateful to the Ministry of Education Malaysia Development Fund F0020 for funding via UPNM/ 2018/CHEMDEF/ST/5.

\section{References}

[1] K. H. Leong, L. L. Benjamin Tan, and A. M. Mustafa, "Contamination levels of selected organochlorine and organophosphate pesticides in the Selangor River, Malaysia between 2002 and 2003," Chemosphere, vol. 66, no. 6, pp. 1153-1159, 2007.

[2] X. Hu, H. Zeng, T. Chen, H.-Q. Yuan, L. Zeng, and G.-M. Bao, "Fast and visual detection of a chemical warfare agent mimic using a simple, effective and portable chemodosimeter," Sensors and Actuators B: Chemical, vol. 319, p. 128282, 2020. 
[3] U.-J. Kim, Y. Wang, W. Li, and K. Kannan, "Occurrence of and human exposure to organophosphate flame retardants/ plasticizers in indoor air and dust from various microenvironments in the United States," Environment International, vol. 125, pp. 342-349, 2019.

[4] Z. Basrai, C. Koh, M. Celedon, and J. Warren, "Clinical effects from household insecticide: pyrethroid or organophosphate toxicity?" BMJ Case Reports, vol. 12, no. 11, Article ID e230966, 2019.

[5] S. Rastogi, S. Tripathi, and D. Ravishanker, "A study of neurologic symptoms on exposure to organophosphate pesticides in the children of agricultural workers," Indian Journal of Occupational and Environmental Medicine, vol. 14, no. 2, p. 54, 2010.

[6] R. K. Jha, T. L. Kern, Y. C. Kim et al., “A microbial sensor for organophosphate hydrolysis exploiting an engineered specificity switch in a transcription factor," Nucleic Acids Research, vol. 1, pp. 1-11, 2016.

[7] M. B. Abou-Donia, "Organophosphorus ester-induced chronic neurotoxicity," Archives of Environmental Health: An International Journal, vol. 58, no. 8, pp. 484-497, 2003.

[8] J. Sutris, V. How, S. Sumeri et al., "Genotoxicity following organophosphate pesticides exposure among orang asli children living in an agricultural island in KualaLangat, Selangor, Malaysia," The International Journal of Occupational and Environmental Medicine, vol. 7, no. 1, pp. 42-51, 2016.

[9] V. How, Z. Hashim, P. Ismail, S. Md Said, D. Omar, and S. Bahri Mohd Tamrin, "Exploring cancer development in adulthood: cholinesterase depression and genotoxic effect from chronic exposure to organophosphate pesticides among rural farm children," Journal of Agromedicine, vol. 19, no. 1, pp. 35-43, 2014.

[10] P. Kumar, K.-H. Kim, and A. Deep, "Recent advancements in sensing techniques based on functional materials for organophosphate pesticides," Biosensors and Bioelectronics, vol. 70, pp. 469-481, 2015.

[11] G. Istamboulie, R. Durbiano, D. Fournier, J.-L. Marty, and T. Noguer, "Biosensor-controlled degradation of chlorpyrifos and chlorfenvinfos using a phosphotriesterase-based detoxification column," Chemosphere, vol. 78, no. 1, pp. 1-6, 2010.

[12] E. Ghanem and F. M. Raushel, "Detoxification of organophosphate nerve agents by bacterial phosphotriesterase," Toxicology and Applied Pharmacology, vol. 207, pp. S459S470, 2005.

[13] X. Zhang, R. Wu, L. Song et al., "Molecular dynamics simulations of the detoxification of paraoxon catalyzed by phosphotriesterase," Journal of Computational Chemistry, vol. 30, no. 15, pp. 2388-2401, 2009.

[14] T. Yamazaki, Z. Meng, K. Mosbach, and K. Sode, "A novel amperometric sensor for organophosphotriester insecticides detection employing catalytic polymer mimicking phosphotriesterase catalytic center," Electrochemistry, vol. 69, no. 12, pp. 969-972, 2001.

[15] P.-C. Tsai, A. Bigley, Y. Li et al., "Stereoselective hydrolysis of organophosphate nerve agents by the bacterial phosphotriesterase," Biochemistry, vol. 49, no. 37, pp. 7978-7987, 2010.

[16] M. Jain, P. Yadav, A. Joshi, and P. Kodgire, "Advances in detection of hazardous organophosphorus compounds using organophosphorus hydrolase based biosensors," Critical Reviews in Toxicology, vol. 49, no. 5, pp. 387-410, 2019.

[17] R. K. Mishra, G. Istamboulie, S. Bhand, and J.-L. Marty, "Detoxification of organophosphate residues using phosphotriesterase and their evaluation using flow based biosensor," Analytica Chimica Acta, vol. 745, pp. 64-69, 2012.

[18] J. Bao, C. Hou, Q. Dong et al., "ELP-OPH/BSA/TiO 2 nanofibers/c-MWCNTs based biosensor for sensitive and selective determination of p-nitrophenyl substituted organophosphate pesticides in aqueous system," Biosensors and Bioelectronics, vol. 85, pp. 935-942, 2016.

[19] Y. Zhang, M. Arugula, and A. Simonian, "Discriminative detection of neurotoxins by a layer-by-layer based carbon nanotube/bi-enzyme biosensor," ECS Transactions, vol. 64, no. 1, pp. 133-141, 2014.

[20] R. Karami, A. Mohsenifar, S. M. Mesbah Namini et al., "A novel nanobiosensor for the detection of paraoxon using chitosan-embedded organophosphorus hydrolase immobilized on Au nanoparticles," Preparative Biochemistry \& Biotechnology, vol. 46, no. 6, pp. 559-566, 2016.

[21] N. Kamelipour, A. Mohsenifar, M. Tabatabaei et al., "Fluorometric determination of paraoxon in human serum using a gold nanoparticle-immobilized organophosphorus hydrolase and coumarin 1 as a competitive inhibitor," Microchimica Acta, vol. 181, no. 1-2, pp. 239-248, 2014.

[22] M. N. Omar, A. B. Salleh, H. N. Lim, and A. Ahmad Tajudin, "Electrochemical detection of uric acid via uricase-immobilized graphene oxide," Analytical Biochemistry, vol. 509, pp. 135-141, 2016.

[23] M. F. Abd Muain, K. H. Cheo, M. N. Omar et al., "Gold nanoparticle-decorated reduced-graphene oxide targeting anti hepatitis B virus core antigen," Bioelectrochemistry, vol. 122, pp. 199-205, 2018.

[24] P. S. Teo, H. N. Lim, N. M. Huang, C. H. Chia, and I. Harrison, "Room temperature in situ chemical synthesis of Fe3O4/ graphene," Ceramics International, vol. 38, no. 8, pp. 6411-6416, 2012.

[25] J. I. A. Rashid, V. Kannan, M. H. Ahmad et al., "An electrochemical sensor based on gold nanoparticles-functionalized reduced graphene oxide screen printed electrode for the detection of pyocyanin biomarker in Pseudomonas aeruginosa infection," Materials Science and Engineering: C, vol. 120, Article ID 111625, 2021.

[26] Q. Zhao, Y. Hou, G.-H. Gong, M.-A. Yu, L. Jiang, and F. Liao, "Characterization of alcohol dehydrogenase from permeabilized brewer's yeast cells immobilized on the derived attapulgite nanofibers," Applied Biochemistry and Biotechnology, vol. 160, no. 8, pp. 2287-2299, 2010.

[27] M. A. Pimenta, G. Dresselhaus, M. S. Dresselhaus, L. G. Cançado, A. Jorio, and R. Saito, "Studying disorder in graphite-based systems by Raman spectroscopy," Physical Chemistry Chemical Physics, vol. 9, no. 11, pp. 1276-1290, 2007.

[28] K. Krishnamoorthy, R. Mohan, and S.-J. Kim, "Graphene oxide as a photocatalytic material," Applied Physics Letters, vol. 98, no. 24, Article ID 244101, 2011.

[29] D. Joung, A. Chunder, L. Zhai, and S. I. Khondaker, "Space charge limited conduction with exponential trap distribution in reduced graphene oxide sheets," Applied Physics Letters, vol. 97, no. 9, Article ID 093105, 2010.

[30] F. Y. Ban, S. R. Majid, N. M. Huang, and H. N. Lim, "Graphene oxide and its electrochemical performance," International Journal of Electrochemical Science, vol. 7, no. 5, pp. 4345-4351, 2012.

[31] Z. Qian, L. Youxiu, Z. Kangyao, L. Meijin, and T. Dianping, "Reduced graphene oxide/BiFeO3nanohybrids-based signalon photoelectrochemical sensing system for prostate-specific antigen detection coupling with magnetic microfluidic 
device," Biosensors and Bioelectronics, vol. 101, pp. 146-152, 2018.

[32] Z. Qian, L. Youxiu, S. Jian, Z. Kangyao, Y. Zhengzhong, and T. Dianping, "Reduced graphene oxide-functionalized $\mathrm{FeOOH}$ for signal-on photoelectrochemical sensing of prostate-specific antigen with bioresponsive controlled release system," Biosensors and Bioelectronics, vol. 98, pp. 15-21, 2017.

[33] A. Omar, J. Rashid, A. Latif et al., "Development of cortisol immunosensor based reduced graphene oxide ( $\mathrm{rGO}$ ) for future application in monitoring stress levels among military personnel," Science \& Technology Research Institute for Defence (STRIDE), vol. 10, no. 2, pp. 142-148, 2017.

[34] A. F. M. Azmi, V. Kannan, N. S. Yasin, J. I. A. Rashid, A. Omar, and E. M. Salleh, "Effect of time and temperature on reduced graphene oxide (rgo) layer stability and cyclic voltammetric behaviour of modified screen-printed carbon electrode (mSPCE) for biosensing purposes," Malaysian Journal of Analytical Sciences, vol. 24, no. 5, pp. 800-809, 2020.

[35] O. Jalil, C. M. Pandey, and D. Kumar, "Highly sensitive electrochemical detection of cancer biomarker based on antiEpCAM conjugated molybdenum disulfide grafted reduced graphene oxide nanohybrid," Bioelectrochemistry, vol. 138, Article ID 107733, 2021.

[36] D. Minta, A. Moyseowicz, S. Gryglewicz, and G. Gryglewicz, "A promising electrochemical platform for dopamine and uric acid detection based on a polyaniline/iron oxide-tin oxide/ reduced graphene oxide ternary composite," Molecules, vol. 25 , no. 24 , p. $5869,2020$.

[37] A. Popov, R. Aukstakojyte, J. Gaidukevic et al., "Reduced graphene oxide and polyaniline nanofibers nanocomposite for the development of an amperometric glucose biosensor," Sensors, vol. 21, no. 3, p. 948, 2021.

[38] M. Fani, M. Rezayi, Z. Meshkat, S. A. Rezaee, M. Makvandi, and K. Ahmadi Angali, "A novel electrochemical DNA biosensor based on a gold nanoparticles-reduced graphene oxide-polypyrrole nanocomposite to detect human T-lymphotropic virus-1," IEEE Sensors Journal, vol. 20, no. 18, pp. 10625-10632, 2020.

[39] N. K. Mogha, V. Sahu, R. K. Sharma, and D. T. Masram, "Reduced graphene oxide nanoribbon immobilized gold nanoparticle based electrochemical DNA biosensor for the detection of Mycobacterium tuberculosis," Journal of Materials Chemistry B, vol. 6, no. 31, pp. 5181-5187, 2018.

[40] F. W. Studier, "Protein production by auto-induction in highdensity shaking cultures," Protein Expression and Purification, vol. 41, no. 1, pp. 207-234, 2005.

[41] T. Laothanachareon, V. Champreda, P. Sritongkham, M. Somasundrum, and W. Surareungchai, "Cross-linked enzyme crystals of organophosphate hydrolase for electrochemical detection of organophosphorus compounds," World Journal of Microbiology and Biotechnology, vol. 24, no. 12, pp. 3049-3055, 2008.

[42] M. H. M. Zaid and J. Abdullah, "Preparation and characterization of amine functionalized graphene oxide with water soluble quantum dots for sensing material," AIP Conference Proceedings, vol. 1877, Article ID 040002, 2017.

[43] M. S. A. Sher Shah, W.-J. Kim, J. Park et al., "Highly efficient and recyclable nanocomplexed photocatalysts of $\mathrm{AgBr} / \mathrm{N}$ doped and amine-functionalized reduced graphene oxide," ACS Applied Materials \& Interfaces, vol. 6, no. 23, pp. 20819-20827, 2014.
[44] C. M. Riccardi, D. Mistri, O. Hart et al., "Covalent interlocking of glucose oxidase and peroxidase in the voids of paper: enzyme-polymer "spider webs"," Chemical Communications, vol. 52, no. 12, pp. 2593-2596, 2016.

[45] L. Aricov, A. R. Leonties, I. C. Gîfu, D. Preda, A. Raducan, and D.-F. Anghel, "Enhancement of laccase immobilization onto wet chitosan microspheres using an iterative protocol and its potential to remove micropollutants," Journal of Environmental Management, vol. 276, Article ID 111326, 2020.

[46] T. J. Park, M. Yang, B. G. Choi et al., "Label-free electrochemical biosensor based on graphene/ionic liquid nanocomposite for the detection of organophosphate pesticides," MRS Proceedings (OPL), p. 1283, 2011.

[47] N. K. Mogha, V. Sahu, M. Sharma, R. K. Sharma, and D. T. Masram, "Biocompatible $\mathrm{ZrO}_{2}$ - reduced graphene oxide immobilized AChE biosensor for chlorpyrifos detection," Materials \& Design, vol. 111, pp. 312-320, 2016.

[48] X. X. Jiao, H. Q. Luo, and N. B. Li, "Fabrication of graphenegold nanocomposites by electrochemical co-reduction and their electrocatalytic activity toward 4-nitrophenol oxidation," Journal of Electroanalytical Chemistry, vol. 691, pp. 83-89, 2013.

[49] F. M. M. Tchieno and I. K. Tonle, "p-Nitrophenol determination and remediation: an overview," Reviews in Analytical Chemistry, vol. 37, no. 2, 2018.

[50] A. J. Ghazizadeh, A. Afkhami, and H. Bagheri, "Voltammetric determination of 4-nitrophenol using a glassy carbon electrode modified with a gold- $\mathrm{ZnO}-\mathrm{SiO} 2$ nanostructure," Microchimica Acta, vol. 185, no. 6, 2018.

[51] J. Wu, Q. Wang, A. Umar et al., "Highly sensitive p-nitrophenol chemical sensor based on crystalline $\alpha-\mathrm{MnO} 2$ nanotubes," New J. Chem.vol. 38, no. 9, pp. 4420-4426, 2014.

[52] M. Yang, B. G. Choi, T. J. Park, N. S. Heo, W. H. Hong, and S. Y. Lee, "Site-specific immobilization of gold binding polypeptide on gold nanoparticle-coated graphene sheet for biosensor application," Nanoscale, vol. 3, no. 7, p. 2950, 2011.

[53] V. Sethuraman, P. Muthuraja, J. Anandha Raj, and P. Manisankar, "A highly sensitive electrochemical biosensor for catechol using conducting polymer reduced graphene oxide-metal oxide enzyme modified electrode," Biosensors and Bioelectronics, vol. 84, pp. 112-119, 2016.

[54] I. Beenish, M. I. Inamuddin, M. I. Ahamed, A. M. Asiri, and K. A. AlAmry, "Biocompatible mediated bioanode prepared by using poly(3,4-ethylene dioxythiophene) poly(styrene sulfonate) (PEDOT:PSS) and sulfonated graphene oxide integrated enzyme for biofuel cells applications," Materials Science for Energy Technologies, vol. 1, no. 1, pp. 63-69, 2018.

[55] E. Gnandt, J. Schimpf, C. Harter, J. Hoeser, and T. Friedrich, "Reduction of the off-pathway iron-sulphur cluster N1a of Escherichia coli respiratory complex I restrains NAD+ dissociation," Scientific Reports, vol. 7, no. 1, pp. 1-10, 2017.

[56] J. H. Lee, J. Y. Park, K. Min, H. J. Cha, S. S. Choi, and Y. J. Yoo, "A novel organophosphorus hydrolase-based biosensor using mesoporous carbons and carbon black for the detection of organophosphate nerve agents," Biosensors and Bioelectronics, vol. 25, no. 7, pp. 1566-1570, 2010.

[57] M. A. Al-Najjari, O. M. Hakami, A. J. Al-Rajab, E. M. Ebada, and T. Zelai, "Enhanced arid areas on-site Aryl-Di-Alkylphosphatase biosensor built on au-nanoparticles decorated graphene hybrid nano-sheets for diazinon detection," Ecology, Environment and Conservation, vol. 25, pp. 68-81, 2019.

[58] M. S. Andrianova, O. V. Gubanova, N. V. Komarova, E. V. Kuznetsov, and A. E. Kuznetsov, "Development of a biosensor based on phosphotriesterase and n-channel ISFET 
for detection of pesticides," Electroanalysis, vol. 28, no. 6, pp. 1311-1321, 2016.

[59] R. Iyer, B. Iken, A. Damania, and J. Krieger, "Whole genome analysis of six organophosphate-degrading rhizobacteria reveals putative agrochemical degradation enzymes with broad substrate specificity," Environmental Science and Pollution Research, vol. 25, no. 14, pp. 13660-13675, 2018.

[60] L. Briseño-Roa, C. M. Timperley, A. D. Griffiths, and A. R. Fersht, "Phosphotriesterase variants with high methylphosphonatase activity and strong negative trade-off against phosphotriesters," Protein Engineering, Design and Selection, vol. 24, no. 1-2, pp. 151-159, 2011.

[61] G. Choo and J.-E. Oh, "Seasonal occurrence and removal of organophosphate esters in conventional and advanced drinking water treatment plants," Water Research, vol. 186, Article ID 116359, 2020.

[62] L. Xing, Q. Zhang, X. Sun, H. Zhu, S. Zhang, and H. Xu, "Occurrence, distribution and risk assessment of organophosphate esters in surface water and sediment from a shallow freshwater Lake, China," Science of the Total Environment, vol. 636, pp. 632-640, 2018. 